\title{
Research on the Development of Rural Cultural Industry Based on Urban-rural Integration
}

\author{
Xiaoyu Wang \\ Huanghe Science and Technology College \\ Zhengzhou, China
}

\begin{abstract}
Comprehensively planning urban and rural culture is the inevitable requirement to promote the development of urban-rural integration. Speeding up the development of urban and rural cultural integration is an important content to construct modern civilized society, and can also constantly promote to create excellent opportunities for the development of rural cultural industry. In the process of integration of urban and rural development, the functions of rural cultural industry point to the prosperity of rural culture, protection of rural cultural ecology, propulsion of the development of rural productive forces, acceleration of the rural modernization and new-type urbanization construction, and the construction of mainstream culture and ideology in new countryside. It is an effective way to promote the healthy development of rural cultural industry through actively implementing and developing the resources, brand, exportoriented development and hierarchical advancing strategy of rural cultural industry.
\end{abstract}

Keywords - urban-rural integration; rural cultural industry; resources development; development research

\section{INTRODUCTION}

Urban-rural integration is a new stage of the development of Chinese modernization and urbanization. Through system reform and policy adjustment, it promotes the urban and rural integration in the development of social undertakings such as planning and construction, industrial development, makes the whole urban and rural economy and society present comprehensive, coordinated and sustainable development. The integration of urban and rural development has effectively promoted the flow and optimization of resources in urban and rural areas and provided new environment and operation platform to promote the development and expansion of rural cultural industry. Therefore, under the new environment and new demand, it is necessary to start from the perspective of urban-rural integration, comprehensively develop the development of rural cultural industry through placing it into the overall planning of the integration of urban and rural culture and the big pattern of the development of national cultural industry.

\section{URBAN-RURAL INTEGRATION AND RURAL CULTURAL INDUSTRY}

\section{A. Urban-Rural Integration}

"Urban-rural integration" refers to a method that plans the industry and agriculture, city and countryside, urban residents and rural residents as a whole, and a process of integration of various elements in urban and rural areas, and it reflects the degree of civilization and progress in where it locates in a qualified sense. Theoretically, the integration of urban and rural culture refers to the overall planning, coordinated development, resources sharing and common prosperity of urban and rural cultural undertakings in one area. The specific signs and substantive characteristics of it include that rural residents and urban residents enjoy equal basic public cultural services and it can meet the basic requirements of their cultural life. It is an inevitable course to solve the development of rural cultural undertakings in our country through fully realizing the important significance of overall planning of urban and rural cultural development and energetically promoting the integration of urban and rural cultural development.

\section{B. Rural Cultural Industry}

In our country, rural cultural industry refers to culture industry in administrative regions such as county, township (town) and village. It not only has common properties of great cultural industry, but also has its uniqueness. Firstly, it is the characteristics of marketization. Rural cultural industry must be legal operation, self-accumulation and selfdevelopment; secondly, cultural product resources embody local and regional characteristics; thirdly, the principal part of rural cultural industry is farmers, and the position is in the countryside; fourthly, cultural productivity created by rural cultural industry is from the countryside and develops it; fifthly, products operated by rural cultural industry have the main contents such as artistic performance, folk arts and crafts, agro-ecology and natural ecological tourism that have the local historical inheritance. Therefore, rural cultural industry not only takes rural traditional culture resources as the acting object, but also includes forms of modern cultural industry, such as cinema, theme park and leisure farm stay, etc. 


\section{The DEVElopment Status of RuRAl CUltural INDUSTRY IN OUR COUNTRY}

Rural cultural industry is the culture created and enjoyed by Chinese ethnic peoples for thousands of years and the creation of the wisdom of people. Many folk art masterpieces have been inherited and retained as "Unique of China". But because rural culture was not valued in the past and predecessors didn't sort out related historical materials to leave them to later generations, quite a few rural cultures were spread on the street stalls and few people could really understand the quintessence of rural culture. It causes that the rural culture is on the edge of being lost to some degree.

\section{A. The Policy Dominance Is Strong and Industrial System Begins to Take Shape}

Rural cultural industry has obvious policy dominance and has obtained rapid development under the support of government policy. As bright representative of rural cultural industry, handicraft industry has made certain achievements. Under the support of "one village with one featured products" policy of the local government, quite a few specialized villages, professional towns and counties with considerable scale have occurred. Besides, rural leisure travel, flower gardening and ecological agriculture sightseeing have better development. The advantages of the policy have promoted the starting of rural cultural industry, but the rural cultural industry in our country is still not largescale and the strength is weak. In developed countries, culture industry has become important or pillar industry of national economy and the proportion in GDP accounts for over or next to 20 percent.

\section{B. The Industrial Distribution Tends to Be Rational, but Regional Development Is Unbalanced}

At present, the eastern, central and western areas in our country respectively centre on thoughts such as develop creative industries, excavate historical and cultural resources, and show national characteristics, vigorously develop rural cultural industry and initially shape distinctive cultural industry belts. Traditional rural culture has diversified artistic forms such as dragon dances, yangko performances, etc. But different areas have different performing art forms. The main markets of rural performance industry include urban largescale commercial celebration, opening ceremony of sport and wedding ceremony.

\section{It Is Not Very Professional and the Intensive Degree Needs Promotion}

Primary participants of rural cultural industry are farmers. At present, most farmers make a living mainly through engaging in farm production. In slack farming season, many farmers choose to work in cities. Only few farmers engage in some cultural industry activities, such as handiworks production and dance rehearsal, which are not very professional. Besides, most of them take family as the organizational form, lack foreign cooperation, which cause small industry scale. Therefore, at present, the degree of development and utilization of rural cultural resources is not enough. It is impossible for cultural resources to be changed into cultural products naturally.

To sum up, the state of cultural industrial development in the urban and rural areas is very unbalanced. It is quite difficult to develop rural cultural industry. The Party and the government have realized the importance to develop rural cultural industry, yearly increased the input intensity for rural culture. They are vigorously promoting the healthy development of rural cultural industry.

\section{PROBLEMS EXISTING IN RURAL CULTURAL INDUSTRY IN OUR COUNTRY}

\section{A. The Attention That We Pay to Rural Cultural Industry Is Insufficient and The Intensity of Specific Strategy Is Not Enough.}

For a long time, the special urban-rural dual economic structure in our country has hindered the development of economy and society in rural areas to some extent. And it also has hindering effect on the development of culture industry. Most of the people think culture industry only exists in cities and only city can develop culture industry. And they even think culture industry is equal to urban cultural industry. Although our country has formulated supportive policies and measures related to the development of rural cultural industry, some local governments still put the main energy on developing urban cultural industry and take no count of the development of rural cultural industry. They haven't introduced corresponding development planning and supportive budget layout of rural cultural industry.

Industry integration derives from technological convergence. With the development of new technology, the development of rural cultural industry and new technology promote the close integration of industries. Competent departments of culture at all levels all successively introduce relevant policies to boost the rapid development of rural cultural industry.

\section{B. Insufficient Industry Observation, Input Intensity and No High Degree of Marketization}

In the exploration and analysis of development patterns of rural cultural industry in our country, as the principal part of rural cultural market, farmers are the consumers as well as beneficiaries. After meeting the physiological needs, vast farmers start to stride forward to spiritual needs of higher level. So in the broad rural cultural market, the demand for consumption is continuously increasing; the power of consumption is continually growing and consumptive level is rising constantly. Meanwhile, developing rural cultural industry can solve the problem of employment of surplus rural labor force on the spot. Under the perspective of industry integration, the integrative development of culture industry and related industries can realize the sharing of public basic resources, improve the utilization rate of funds, relieve financial pressures of governments and rapidly break through the bottleneck of industrial development. 


\section{Infrastructures in Rural Areas Are Unsound and Complementary Condition of Cultural Industrial Development Is Poor}

The inequality of distribution of urban and rural public services causes that infrastructures in rural areas is poor and it has restricted the development of rural cultural industry. Many rural areas with rich traditional cultural resources have backward infrastructures, and the construction of highway, electricity, radio and television and communication lags behind. For example, minority areas in Midwest of China have quite rich cultural resources to develop culture industry, but because they are located in mountainous areas where the traffic is blocked, and the poor infrastructures cannot meet the complementary condition required by the development of culture industry, it is impossible for cultural industrial development to start and it cannot realize the objective of "go out" even with better development.

\section{Cultural Resources Are Rich. but Lack Protection for Cultural Heritage And Cultural Products Are Poor}

Cultural resource is the generic terms of tangible cultural heritages and intangible cultural heritages created by humans. The vast rural areas in our country are rich in cultural resources, especially intangible cultural resources, most of which are rooted in rural areas and have diversified pattern of manifestation. However, there are related cultural products to bring culture in rural areas out of the dilemma. Besides, intangible cultural heritage is the witness of national history and valuable spiritual wealth of a nation. Rural areas in our country have rich intangible cultural heritage resources, but the nearsightedness of economic interest makes people in many areas excessively keen on the development of modern cultural industry projects, such as the construction of cinema and film and television city, which lead to the situation that many intangible cultural heritage resources aren't excavated and protected and even appear the discontinuity of heritage.

\section{E. Talent Team Construction Related to Rural Cultural Industry Lags Behind}

Talent is the first source of the rural cultural industry development and also the most important resource. At present, because of the shortage of talents, it is impossible to industrialize the rich traditional cultural resources; on the other hand, we lack professional planning and research institutions for rural cultural industry, make some talents who are willing to devote themselves to the development of rural cultural industry have no arrangements of stable job, so the talent team construction lags behind.

\section{Measures For the DeVElopMent OF RURAL CULTURAL INDUSTRY UNDER THE BACKGROUND OF URBAN-RURAL INTEGRATION}

\section{A. Comprehensively Arrange the Planning and Layout of Urban and Rural Cultural Industry, Promote the Development of Rural Cultural Industry}

The market economy itself has the characteristics of spontaneity, randomness and blindness. It is impossible to eliminate the dual structure of the development of urban and rural cultural industry only by relying on market force. Therefore, it is essential to start from the perspective of urban and rural overall development and do overall planning and layout for urban and rural cultural industry.

First of all, we must give full play to macro coordination function of the government and realize urban and rural overall planning. The overall planning of the development of urban and rural cultural industry is a systems engineering, which needs the coordination and cooperation of all departments and all walks of life in the whole society. Therefore, urban and rural governments must establish working mechanism that can impel the urban-rural integration, strengthen macro coordination and eventually achieve urban-rural integration and the objectives of common prosperity. Secondly, governments must bring the development of rural cultural industry into the big pattern of the development of cultural industry throughout the country; achieve resource sharing, platform sharing, information sharing and the sharing of support and preferential policy. According to urban and rural development strategy, governments should revise implementary plan to perfect the development of rural culture, make it echo with the development of urban culture to form a new situation of the distinctive development of urban and rural cultural industry and each has its advantages.

\section{B. Positively Develop Cultural Industry with Its Own Characteristics in Rural Areas, Promote the Branding of Rural Cultural Industry}

Cultural industry is an industrial system with wide coverage. At present, the problem demanding prompt solution in rural cultural industry is to find the most suitable breakthrough point of the market, and closely integrate the peculiar advantages of cultural industry with the vast rural market.

Rural areas have rich local cultural resources with fullbodied local characteristics. These cultural resources with differentiation competitive advantages are important backings to develop rural cultural industry. The development of rural cultural industry must take market demand as the direction, pay attention to the effective integration and deep procession for resources, continuously improve the quality levels of cultural products and services, strengthen the overall strength and market competitiveness of cultural industry with its own characteristics, create their own brand, get the best social and economic benefits and then realize the change from resource type to benefit type and from resource superiority to economic superiority. 


\section{Implement the "Hierarchical Advancing" Strategy to Form Radiation Situation of Cultural Center}

The implementation of "hierarchical advancing" strategy is to form cascade level of county, township and village in the master plan of development of rural cultural industry. Each level takes a center as the original point, which radiates to the surroundings successively to form an organic linkage system of the whole region with clear developing rhythm, explicit industrial objective and close connection from top to down. Its contents are shown as follows: the first level takes the county as the center to radiate to central market towns; the second level takes the central market town as the center to radiate to the vast rural areas, and then form diversified new situation of the development of rural cultural industry.

\section{Vigorously Cultivate Talents of Rural Cultural Industry And Promote Benign Development of Rural Cultural Industry}

The economic construction, political construction, cultural construction, social construction and Party construction in new rural areas finally must implement on the cultivation of new type farmers and closely centre on the overall objective that farmers get rid of property and become better off and rural areas get development. Vigorously cultivating new type farmers required by the development of rural cultural industry is a systems engineering, which needs various efforts and cooperation. It is necessary to strengthen the excavation and cultivation of practical talents of rural culture, make efforts to cultivate new type of folk artisans in rural areas, reinforce sustainable development capacity of rural culture and motivate the cultural vitality of rural areas.

\section{CONCLUSION}

Under the perspective of urban-rural integration, the industrialization of rural culture is the inevitable requirement to build a new socialist countryside and promote the development of economy and society in rural areas, also the inexorable trend of the rural cultural construction today. The development of rural cultural industry should rely on accumulation of advanced productivity in urban areas and the driven advantages of radiation, give full play to the leading role of "growth pole", and realize the attraction and radiation to the economy in rural areas around it. In the process of developing rural cultural industry, we should take farmers as the principal part of creation and production, take market as the guidance, focus on improving economic efficiency, and adjust measures to local conditions. In addition, use diversified forms to form the pattern that urban areas help rural areas, rural areas promote urban areas, urban and rural areas combine and interact with each other, make various economic subjects, industries and production factors form all-around and multi-level cooperation and distinctive urban and rural cultural industry and each has its advantages. At last, realize the coordinated development and mutual improvement of urban and rural areas.

\section{REFERENCES}

[1] Lei Fang. Difficulties and Outlets of Rural Cultural Industry under the Perspective of Urban and Rural Overall Development [J], Productivity Research, 2011(9)

[2] Zhang Yongli, Gan Lu. Summary on the Research of Rural Cultural Industry in China [J], Inquiry into Economic Issues, 2012(3)

[3] Wang Yachuan. Discussion on Strategic Adjustment of Developed Cities in China-from "Share Richness in Economy" to "Share Richness in Culture" [J], Modern Urban Research, 2007(5)

[4] Zheng Fengtian, Liu Lulin. Rural Culture in New Rural Construction Current Situation, Problem and Countermeasure [J], Journal of Southcentral University for Nationalities (Humanities and Social Sciences Edition, 2008(1))

[5] Huang Xinghua. Rural Autonomous Cultivation: Research on Constructing Inner Driving Force of New Rural Cultural Lifestyle [J], Journal of Yunnan Administrative College, 2012(4)

[6] Zhong Ping. Brief Discussion on Protection and Inheritance of Intangible Cultural Heritage in Construction of Socialism New Countryside [J], Ancient and Modern Agriculture, 2007 (2)

[7] Tan Zhiyun. Functional Orientation and Development Path of Rural Cultural Industry [J], Social Sciences in Nanjing, 2007(3) 